\title{
CORRESPONDENCE
}

Correspondents are asked to be brief

Induction of Therapeutic Abortion with

Urea

M. A. Pugh, F.R.C.s., and others... . . . . 345

Endocrine and Metabolic Disorders in Bronchial Carcinoma

P. v. Wichert, M.D., and P. F. Mitchell-Heggs,

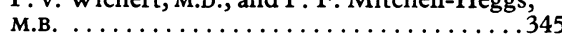

Screening for Breast Cancer

J. Gershon-Cohen, M.D. . . . . . . . . . . . 346

Interaction between Phenytoin and the Benzodiazepines

F. J. E. Vajda, M.R.A.C.P., and others . . . . 346

Infectious Mononucleosis

S. Talbot, M.R.C.P.............. 346

Small Drumsticks and Long Y Chromosomes

N. Ricci, M.D., and others . . . . . . . . . 346
Heel Cushion for Use on the Operating-

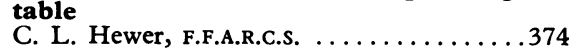

Unusual Treatment of Paroxysmal

Tachycardia

Laparoscopy Hazard

R. Loveday, F.F.A.R.C.s. . . . . . . . . 348

Phenacetin and Papillary Necrosis

M. Goldberg, M.D., and D. McCarron . . . 348

Childhood Enuresis

Margaret S. White, M.B. . . . . . . . 348

Atrial Myxomas

R. B. Pridie, F.F.R. . . . . . . . . . . 348

Secretion of Parathyroid Hormone by a

Renal Adenocarcinoma
G. A. MacGregor, M.D...

Hyperinsulinism and Atherogenesis

J. Yudkin, M.D., and S. Szanto, M.D. . . ...349
Peritonitis in Hyperosmolar Non-ketotic

Diabetic Coma

T. D. Heller, M.B. . . . . . . . . . . . . . . . 349

Action of Bromhexine on Mucus

P. D. Salpekar, M.B. . . . . . . . . . 349

Pancytopenia and Meprobamate

C. Anastassiades, M.D. . . . . . . . . . 349

Diabetes Mellitus and Cancer

L. Wislicki, M.D. . . . . . . . . . . . . . . 349

Pulmonary Tuberculosis Follow-up

H. Chakraborty, M.B., F.C.C.P. . . . . . . 350

Students Doing House Jobs

H. A. Constable, M.R.C.s. . . . . . . . . 350

Personal Health Services

B. D. M. Williams, M.R.C.G.P. . . . . . 350

Family Doctors' Pensions

K. C. Hutchin, M.D. . . . . . . . . . . . 350

\section{Induction of Therapeutic Abortion with Urea}

SIR,-With reference to the article by $\mathrm{Mr}$. J. D. Greenhalf and Mr. P. L. C. Diggory (2 January, p. 28) since March 1970 we have terminated 61 mid-trimester pregnancies where therapeutic abortion was required, using a hypertonic urea solution. Eighty grammes of urea, dissolved in $210 \mathrm{ml}$ $5 \%$ dextrose (Ureaphil), was given by abdominal amniocentesis, the patients being given basal sedation with Valium (diazepam) $10 \mathrm{mg}$ and Fortral (pentazocine) $30 \mathrm{mg}$ intravenously and local anaesthe tic to the skin. After urea instillation the blood urea was measured at planned intervals for 24 hours to assess the rate of excrot:-

In

In ur experience, the induction-abortion delivery interval was so long that stimulation of labour with intravenous Syntocinon (synthetic oxytocin) was necessary. A high

Analysis of the Induction-abortion Interval in 51 Patients

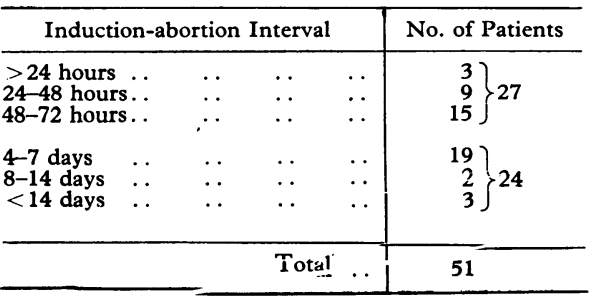

dose of Syntocinon was effective $(50 \mathrm{u} / 1$. of dextrose saline) and the infusion was given over four hours. It was reepated on successjye days if necessary.

\section{Endocrine and Metabolic Disorders in Bronchial Carcinoma}

SIR,-We are surprised at the high incidence of hypercalcaemia reported by Dr. J. G. Azzopardi and others (28 November,
At first we were exploring the method. When we experienced the long delay between amniocentesis and abortion in some cases, we decided to give a high-dose Syntocinon infusion after five days. Now our practice is to start this 24 hours after urea instillation, with considerable improvement in results.

Out of our total series of 61 patients 14 required dilatation and curettage; 1 required hysterotomy, when a dead fetus was delivered; 1 had a second urea instillation, with good effect; and 1 (included in this sami-. but operatad (-... oped intrauterine infection; she aborted the fetus in the lavatory and did not report this fact to the nursing staff. The placenta was retained for several hours. The infection responded rapidly to an antibiotic and the placenta delivered spontaneously, but a curettage was performed to ensure complete evacuation of the uterus.

We plan to publish our results in a specialist journal, but haye delayed doing so until we had defiried a method which took account Gi and dealt with the problems inivoked by this regimen. In our view the routine administration of a high-dose Syntocinon infusion is valuable in ensuring rapid completion of the termination of pregnancy.-We are, etc.,

Michael Pugh SIMON KHUNDA ROGER BALDWIN

Royal Northern Hospital, Holloway Road,
London N.7

p. 528). Despite the by now well-established situation of parathormone activity being often related to squamous cell carcinoma, in most cases it is very difficult to distinguish between hypercalcaemia due to bone metastases and that due to the endocrine disorder following excessive secretion of inappropriate parathormone. In our view it is impossible to differentiate between these possibilities using clinical variables alone without determining the level of parathormone activity. Unfortunately, not only is the estimation of parathormone activity difficult, but also bronchial carcinoma frequently metastasises to bone. Tumours which are large and have been growina fo- some time are frequently associated with clinically undetected bony metastases. Furthermore, there is no correlation between the size of a tumour or a metastasis and its biochemical activity. It is a characteristic feature of endocrine paraneoplastic syndromes that they are associated with small tumours; when these tumours do produce hormones, the rate of production is excessive and is not related to the size of the tumour.

In a series of 300 cases of bronchial carcinoma which one of us (P.v.W.) has seen in Hamburg there have been no definite instances of hypercalcaemia due to paraneoplastic endocrinopathy. According to the literature which has been published to date, the incidence of paraneoplastic hyperparathyroidism is very low $7 \%$ of all tumour-related endocrinopathies ${ }^{2}$ ).-We are, etc.,

\section{Universitätskrankenhaus,
Hamburg-Eppendorf, Germany}

Peter von WicherT

Peter Mitchell-Heggs

Brompton Hospital,
London S.W.3

1 Omenn, G. S., and Wilkins, E. W., fournal of Thoraci
877.

2 Kracht, J., Medizinische Klinik, 1968, 63, 41. 